\title{
HISTÓRIA
}

\section{ALÉM DO SAMBA: A MÚSICA NEGRA NAS AMÉRICAS NO PERÍODO PÓS-ABOLIÇÃO}

"Entram em fila, figura após figura, os sexos intercalados, as mãos dadas por sobre os ombros e, a cada passo de avanço, as cabeças se inclinam - do par à frente sobre a face do de trás - do par atrás sobre a face do da frente. A cada confronto rítmico dos rostos, os olhos se fitam, em flertes fugazes, com expressões momentâneas de convite, enquanto os lábios sorriem...". Era com um misto de empolgação e choque que a coreografia da dança cakewalk era descrita em um artigo publicado em 1904 na glamorosa revista Kosmos, anunciando a moda que chegava dos Estados Unidos e já começava a embalar os salóes cariocas.

A irreverência dos novos passos logo conquistou as elites brasileiras, acostumadas com a rigidez e a formalidade de danças tradicionais, como as valsas e as polcas europeias. Ironicamente, os movimentos exagerados do cakewalk haviam surgido como uma zombaria, feita pelos escravos, do jeito pomposo com que os senhores se posicionavam durante as quadrilhas. Criado nas senzalas americanas no século XIX, era praticada geralmente nos dias de descanso, durante as festas promovidas na casa grande em que eram permitidas exibições dos cativos. No começo era uma espécie de competição cruel: os dançarinos ti- nham que caminhar em linha reta, equilibrando na cabeça um balde d'água enquanto movimentavam o restante do corpo. O cake (bolo, em inglês), artigo raro em meio às privações do trabalho forçado nas plantações, ficava como troféu para o dançarino mais performático.

A partir do modernismo, as culturas dos povos africanos e afro-americanos passaram a ser apropriadas pelas vanguardas artísticas. Logo uma vasta plateia que vivia nas grandes metrópoles adotaria o "estilo africano" na ânsia de ser moderna. Em 1890, o cakewalk já podia ser assistido nos palcos de Nova York como principal atração de um dos conhecidos teatros musicados, The creole show. No jornal parisiense Le Rire, uma edição especial de 1903 foi dedicada à dança, descrita como uma das primeiras formas de entretenimento negro a fazer sucesso na Europa. Aqui no Brasil, foi até incorporado nos bailes de carnaval: em 1903 o Jornaldo Brasil publicou 17 anúncios fazendo referência a festas dedicadas ao ritmo na capital carioca. A febre na época foi tamanha que o músico Pixinguinha compôs uma partitura intitulada Cakewalk.

"O sucesso do cakewalk entre o público branco, jovem e urbano representava uma fascinação racista pelo exótico, além de uma subversão dos velhos valores burgueses. Um processo muito parecido com o sucesso do funk carioca entre a classe média, por exemplo. A nova dança também representava uma mudança de comportamento: as mulheres passaram a ter mais autonomia na cidade, uma vida com menos restrições sociais do que no campo. $\mathrm{O}$ mercado logo percebeu o interesse e passou a investir em gêneros que também fossem dançáveis", explica Martha Abreu, autora do livro $D a$ senzala ao palco: cançôes escravas e racismo nas Américas, 1870-1930.

Publicado pela Editora da Unicamp, o e-book faz parte da coleçãoHistóri@ Ilustrada e analisa a ascensão, a duras penas, das músicas produzidas por escravos e seus descendentes nas Américas no período após a Abolição até o início $\mathrm{da}$ indústria fonográfica, por meio de uma comparação das transformaçôes sociais e culturais ocorridas nos Estados Unidos e no Brasil.

IDEIAS MODERNISTAS, PRECONCEITOS ANTIGOS A historiadora, professora do Departamento de História da Universidade Federal Fluminense (UFF), ressalta que o interesse pelas cançôes escravas no Ocidente - definidas em sua pesquisa como músicas, danças e gêneros musicais identificados com memórias do cativeiro - era marcado por antigos preconceitos, mesmo que representasse ideais modernos. Vista como atraente, primitiva, sensual e emocional, a cultura negra tornou-se o caminho pelo qual a sociedade branca representava sua própria superioridade e se sentia autorizada a ridicularizar essas estéticas. 

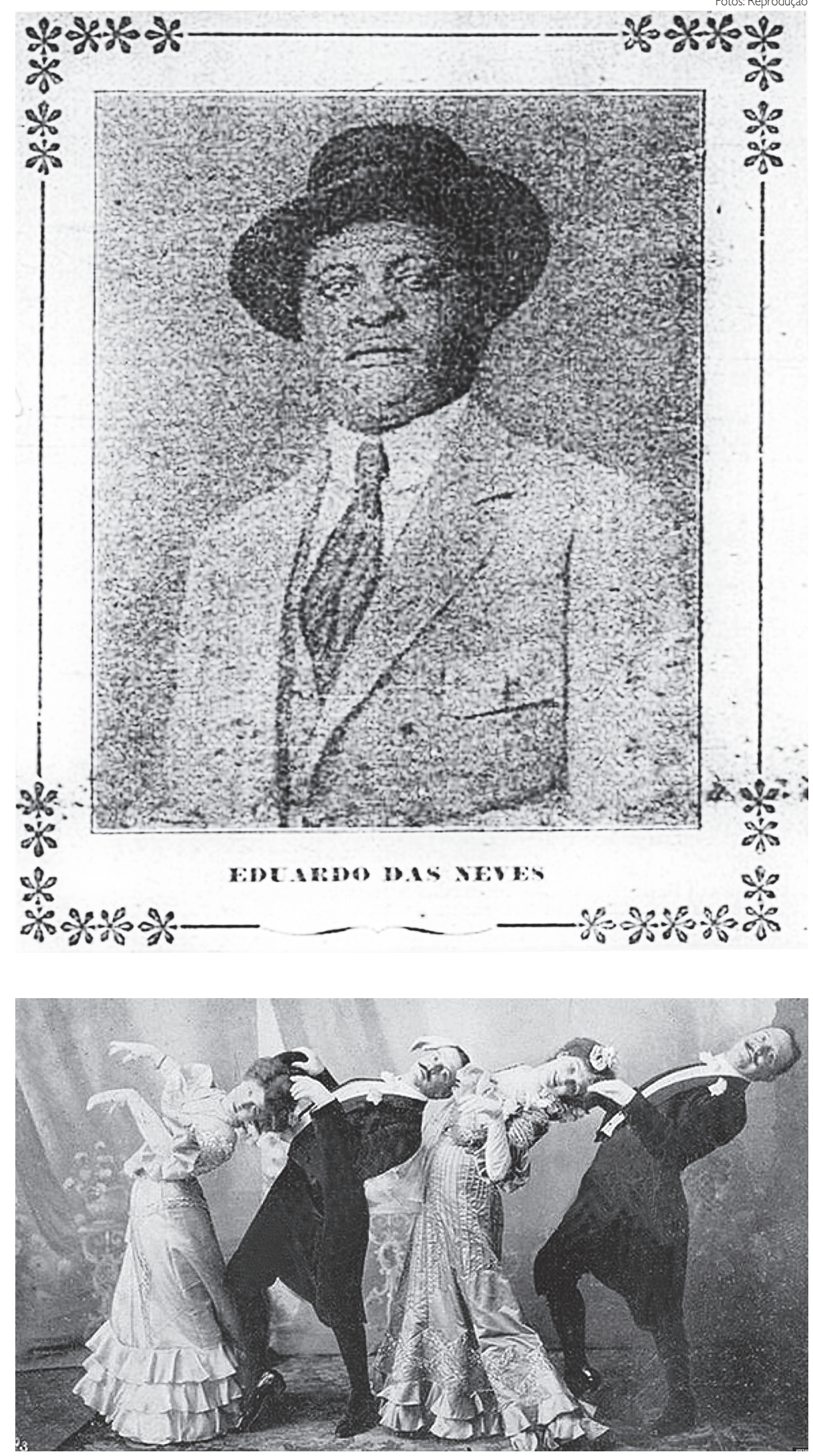

O mesmo acontecia com os espetáculos blackface encenados nos Estados Unidos. Ainda que as cançóes escravas fossem populares, a presença de negros nos palcos de prestígio era rara na segunda metade do século XIX. Menestréis brancos costumavam interpretar os papéis de negros, pintando o rosto com graxa preta e com lábios e olhos exagerados, em caricaturas grotescas. No Brasil, há registro de palhaços pintados de preto que alcançaram reconhecimento no mundo do circo, fazendo graça para as plateias brancas. Em uma crítica publicada em 1875 sobre a peça Demônio familiar, do escritor José de Alencar, o jornalista Joaquim Nabuco reprovava o uso de linguajar chulo dos clowns pintados de preto.

Apesar da dura realidade, o meio musical ainda apresentava uma das poucas possibilidades de mobilidade para os negros no período pós-abolição. As canções escravas impulsionaram todo um mercado, dando visibilidade aos descendentes de africanos. Antes da invenção do fonógrafo por Thomas Edison, em 1877 , a indústria musical já prosperava com a venda de partituras para pianos. Graças ao boom da economia cafeeira no final do século XIX, a sociedade abastada do Rio de Janeiro mostrava seu enriquecimento comprando pianos e um de seus maiores passatempos eram os bailes e os saraus feitos em casa. Em meio às valsas e às árias italianas e francesas,

Acima, Eduardo das Neves o "rei do lundu" e, ao lado, cartão-postal de 1903 com passos do cakewalk que embalava os salões cariocas no começo do século XX 
começaram a ganhar cada vez mais espaço na sala de estar das famílias os ritmos afro-brasileiros mais dançantes como lundus, tangos, batuques, jongos, maxixes e sambas.

“O PRETO JÁ É LIVRE" Eduardo das Neves (1874-1919) foi um dos cantores de maior sucesso no Brasil nesse período, mesmo antes da chegada do rádio ou do disco. Conhecido como o "rei do lundu", compôs 300 partituras ao longo da carreira, tornando-se o primeiro cantor negro a gravar um disco no início dos anos 1900. "O sucesso de músicos como Eduardo das Neves não pode ser pensado apenas a partir do interesse de intelectuais modernistas ou de interesses mercadológicos. Além do talento, sua projeção é fruto da luta de gerações para ter acesso à cidadania", define Abreu.

E o "crioulo Dudu", como se autointitulava, fazia questão de mostrar o quanto era bem sucedido. Proprietário do Circo Brasil, era conhecido pela elegância: fez do fraque azul e da cartola sua marca registrada. As suas músicas também refletem o orgulho de suas raízes africanas de uma forma ufanista, como é o caso de seu maior hit o lundu Canoa virada, lançado em 1907 em homenagem à abolição da escravatura. Nos versos, Dudu, com seu vozeirão, clama: "o preto já é livre, já não tem senhor”. Também influenciou toda uma geração de músicos que iriam se tornar futuros astros do samba nos anos 1920. João da Baiana trabalhou no circo de Dudu como palhaço. Sinhô, que depois recebeu o títu- lo de "rei do samba", acompanhou Eduardo das Neves portando a bandeira brasileira numa famosa homenagem a Santos Dumont, em 1903. Mas isso não impediu que, após a sua morte, Eduardo das Neves tenha se tornado um ilustre desconhecido. "A emergência do samba como gênero nacional vai varrer todo um passado musical para debaixo do tapete. Dudu foi um desses músicos a quem não foi atribuído um papel mais significativo. Foi menosprezado após sua morte, relegado pela história apenas por ter sido intérprete de lundus e canções ufanistas", afirma Abreu.

Apesar de o cantor não receber o merecido reconhecimento, o impacto do trabalho de artistas pioneiros como ele ecoa alto até hoje. "O sucesso de músicos como Eduardo das Neves não pode ser pensado apenas a partir do interesse de intelectuais modernistas ou de interesses mercadológicos. Além do talento, sua projeção é fruto da luta de gerações para ter acesso à cidadania. E se o racismo ainda teima em permanecer, é justamente no campo musical que parece residir uma das melhores formas de resistência e subversão. O impacto das imagens e dos movimentos do videoclipe dos cantores norte-americanos Beyoncé e Jay-Z, gravado no Louvre e lançado em junho deste ano, não poderia ser melhor exemplo da luta dos músicos negros por outra representação no campo artístico", conclui a historiadora.

Leonardo Fernandes

\section{RESENHA}

UMA

\section{AUTORREFLEXÃO PELA AUTONOMIA UNIVERSITÁRIA}

A universidade está em crise. No Brasil, em países da América Latina e da Europa, enfim, no mundo inteiro se ouve e se lê essa frase. Para olhares desatentos ou afastados, a história da instituição universitária parece ser uma sucessão de tropeços que a leva de uma crise a outra ou, pior, a história de uma única e interminável crise, que a acompanha há séculos.

Há outra forma mais adequada, no entanto, de interpretar esse estado permanente de crise na universidade. A palavra crise, segundo o dicionário Houaiss, chegada a nós do latim crisis, por sua vez uma recepção do grego krísis, tem na sua origem o sentido de "momento de decisão, de mudança súbita”. Num contexto semântico mais amplo, refere-se à "ação ou faculdade de distinguir, decisão”. É nesse sentido que melhor interpretaremos a tão aludida crise na universidade: não como um momento de desequilíbrio e transição, à maneira econômica e sociológica, mas como o permanente exercício dessa faculdade de distinção. Em outras palavras, a universidade está sempre em crise porque está sempre refletindo sobre si mesma, examinando a si mes- 